\title{
Article \\ Insight into Factors Influencing Wound Healing Using Phosphorylated Cellulose-Filled-Chitosan Nanocomposite Films
}

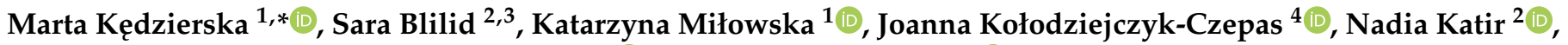 \\ Mohammed Lahcini ${ }^{3}$, Abdelkrim El Kadib ${ }^{2}$ (D) and Maria Bryszewska ${ }^{1}$ (D) \\ 1 Department of General Biophysics, Faculty of Biology and Environmental Protection, University of Lodz, \\ 90-236 Lodz, Poland; katarzyna.milowska@biol.uni.lodz.pl (K.M.); maria.bryszewska@biol.uni.lodz.pl (M.B.) \\ 2 Euromed Research Center, Engineering Division, Euro-Med University of Fes (UEMF), Fès 30070, Morocco; \\ blilidsara@gmail.com (S.B.); n.katir@ueuromed.org (N.K.); a.elkadib@ueuromed.org (A.E.K.) \\ 3 Laboratory of Organometallic and Macromolecular Chemistry-Composites Materials, Faculty of Sciences and \\ Technologies, Cadi Ayyad University, Marrakech 40000, Morocco; m.lahcini@uca.ma \\ 4 Department of General Biochemistry, Faculty of Biology and Environmental Protection, University of Lodz, \\ 90-236 Lodz, Poland; joanna.kolodziejczyk@biol.uni.lodz.pl \\ * Correspondence: marta.kedzierska@biol.uni.lodz.pl
}

check for

updates

Citation: Kędzierska, M.; Blilid, S.; Miłowska, K.; Kołodziejczyk-Czepas, J.; Katir, N.; Lahcini, M.; El Kadib, A.; Bryszewska, M. Insight into Factors Influencing Wound Healing Using Phosphorylated Cellulose-FilledChitosan Nanocomposite Films. Int. J. Mol. Sci. 2021, 22, 11386. https:// doi.org/10.3390/ijms222111386

Academic Editor: Hitoshi Sashiwa

Received: 29 September 2021

Accepted: 18 October 2021

Published: 21 October 2021

Publisher's Note: MDPI stays neutral with regard to jurisdictional claims in published maps and institutional affiliations.

Copyright: (c) 2021 by the authors. Licensee MDPI, Basel, Switzerland. This article is an open access article distributed under the terms and conditions of the Creative Commons Attribution (CC BY) license (https:// creativecommons.org/licenses/by/ $4.0 /)$.
Abstract: Marine polysaccharides are believed to be promising wound-dressing nanomaterials because of their biocompatibility, antibacterial and hemostatic activity, and ability to easily shape into transparent films, hydrogels, and porous foams that can provide a moist micro-environment and adsorb exudates. Current efforts are firmly focused on the preparation of novel polysaccharide-derived nanomaterials functionalized with chemical objects to meet the mechanical and biological requirements of ideal wound healing systems. In this contribution, we investigated the characteristics of six different cellulose-filled chitosan transparent films as potential factors that could help to accelerate wound healing. Both microcrystalline and nano-sized cellulose, as well as native and phosphorylated cellulose, were used as fillers to simultaneously elucidate the roles of size and functionalization. The assessment of their influences on hemostatic properties indicated that the tested nanocomposites shorten clotting times by affecting both the extrinsic and intrinsic pathways of the blood coagulation system. We also showed that all biocomposites have antioxidant capacity. Moreover, the cytotoxicity and genotoxicity of the materials against two cell lines, human BJ fibroblasts and human KERTr keratinocytes, was investigated. The nature of the cellulose used as a filler was found to influence their cytotoxicity at a relatively low level. Potential mechanisms of cytotoxicity were also investigated; only one (phosphorylated microcellulose-filled chitosan films) of the compounds tested produced reactive oxygen species (ROS) to a small extent, and some films reduced the level of ROS, probably due to their antioxidant properties. The transmembrane mitochondrial potential was very slightly lowered. These biocompatible films showed no genotoxicity, and very importantly for wound healing, most of them significantly accelerated migration of both fibroblasts and keratinocytes.

Keywords: chitosan; cellulose; phosphorylated cellulose; bio-composites; wound-healing

\section{Introduction}

The skin, the largest organ of the human body, has many important functions. First, it creates a barrier against the penetration of pathogens as well as chemical and physical factors. It is also involved in regulating body temperature, perceives external stimuli, protects against water loss, affects the hormonal balance, and contributes to the immune system [1-3]. Due to the complexity and importance of these functions for the organism, the organ must function properly and, especially, must ensure its full continuity. Therefore, many mechanisms have evolved to ensure effective healing of wounds and skin defects. 
Proper wound healing protects organisms against pathogens that can cause local and systemic infections, including sepsis $[4,5]$.

One of the problems in modern medicine is the process of healing chronic wounds. Each year, millions of people worldwide experience both acute and chronic skin injuries, and $\sim 37$ million people suffer from chronic wounds [6]. Chronic wounds most often affect the elderly. The rate of their occurrence is constantly increasing due to the aging of society and the ages of patients $[7,8]$. "Non-healing" wounds most often concern patients suffering from peripheral arteriosclerosis, diabetic foot, and people immobilized with bedsores [9].

Wound healing is a very complicated process due to the involvement of many factors and the complexity of the associated mechanisms. The repair process depends on many types of cells and factors, including fibroblasts, growth factors, cytokines and elements of the extracellular matrix [10]. During healing, complex reactions of chemically and biologically active substances take place as well as physical phenomena expressed by an increase in tensile strength and changes in skin elasticity.

Healing mechanisms can be divided into three main phases: debridement (hemostasis), cell proliferation (migration), and restoration (protein generation and wound contraction with scar formation) [11]. Damage to the skin is associated with the rupture of blood vessels and bleeding, which are inseparable features of a wound. Hemostasis and inflammation then occur.

Hemostasis, its main goal being to create a lamellar plug that protects the wound against external factors and stops bleeding, begins immediately after injury. At the same time, monocytes, neutrophils, and mast cells diffuse into the plug-forming site. The hemostatic response, including the activation of blood platelets, triggers the plasma coagulation cascade and generation of the thrombin enzyme, which are important elements that stimulate tissue remodeling and wound healing [12]. The clot is a temporary structure that allows the migration of biomolecules and is the basis of wound healing factors [5]. One of main cellular factors involved in the healing mechanism is platelet-derived growth factor (PDGF) in the blood. The essence of its presence is the activation of fibroblasts and macrophages, triggering a further stage of the tissue repair process by creating the extracellular matrix (ECM) [13,14].

The next stage is cell proliferation and reconstruction of connective tissue containing collagen fibers. Macrophages determine the transition from the purification phase to the multiplication phase.

Proliferation leads to the formation of a base called granulation tissue, on which new epidermis is reconstructed. Within two weeks of injury, mast cells become active, stimulating the rapid multiplication of keratinocytes and fibroblasts. The substrate for this reconstruction of the epidermis consists of a network of collagen fibers, glycoprotein contained in the extracellular matrix (fibronectin), and hyaluronic acid. An integral process in the proliferation phase is angiogenesis $[15,16]$. In the final stage of wound healing, the extracellular matrix is restructured, and type I collagen is produced. The wound is completely closed with the participation of contractile myofibroblasts [2].

Current therapeutic strategies are insufficiently effective, making it necessary to focus on new therapeutic approaches and develop technologies for treating both persistent short- and long-term wounds. In this framework, the inherent properties of natural polysaccharides seem to be attractive; their use has already stimulated extensive research to find improved devices [17-22].

Chitosan extracted from crustaceans is one of the most interesting polysaccharides, owing to the abundance of its source, the presence of nitrogen in the skeletal structures, and is ease of shaping into hydrogels, porous beads, and transparent films [23,24]. Its potential drawback lies in its poor mechanical properties, which can be circumvented by adding a tiny amount of nanometric filler (e.g., graphene oxide, ceramic metal oxide, clay, calcium carbonate, metals, and hard carbon) [25-28]. We previously investigated the entrapment and growth of different objects inside chitosan films to access highly reactive bioplastics [29-32]. With the aim of avoiding any undesirable or side effects that might 
emanate from the filler nature, we further explored the use of naturally abundant and biodegradable micro- and nanocellulose as fillers, allowing access to fully compatible cellulose-filled chitosan nanocomposites [33]. Interestingly, phosphorylated cellulose fillers also enhance the antibacterial activity of chitosan films, making these materials active without the entrapment of silver nanoparticles, zinc oxide clusters, or any other costly synthetic metals. Additionally, these films are transparent, which is very convenient when used as wound dressings to directly observe the wound and accurately monitor its healing. Herein, we investigated the use of phosphorylated and native cellulose-filled chitosan biocomposites as potential materials to accelerate wound healing. These biomaterials were tested for their hemostatic properties, cytotoxicity against two cell lines (fibroblasts and keratinocytes), antioxidant properties, and influence on cell migration.

\section{Results and Discussion}

For our study, we selected seven chitosan-based films (Figure 1). One of them, denoted as CS, was built by casting a colloidal solution of chitosan; it served as a benchmark. We also added $3 \mathrm{wt} \%$ microcrystalline cellulose (MCC) and nanosized cellulose (CNC) to the starting chitosan cellulose to create CS@MCC and CS@CNC, respectively. Herein, any comparison should reflect the pivotal role played by the size of the filler and could highlight interest in downsizing cellulose to the nanoscale. We also modified both MCC and CNC with $\mathrm{POCl}_{3}$ to produce P-MCC and P-CNC and used cyclo- triphosphazene ring to access $\mathrm{PN}-\mathrm{MCC}$ and PN-CNC [34]. These phosphorylated celluloses were also used as fillers to build novel cellulose-filled chitosan films. Any discrepancy in material performance could be attributed to filler functionalization. Detailed characterization of these materials has already been described in $[33,34]$.
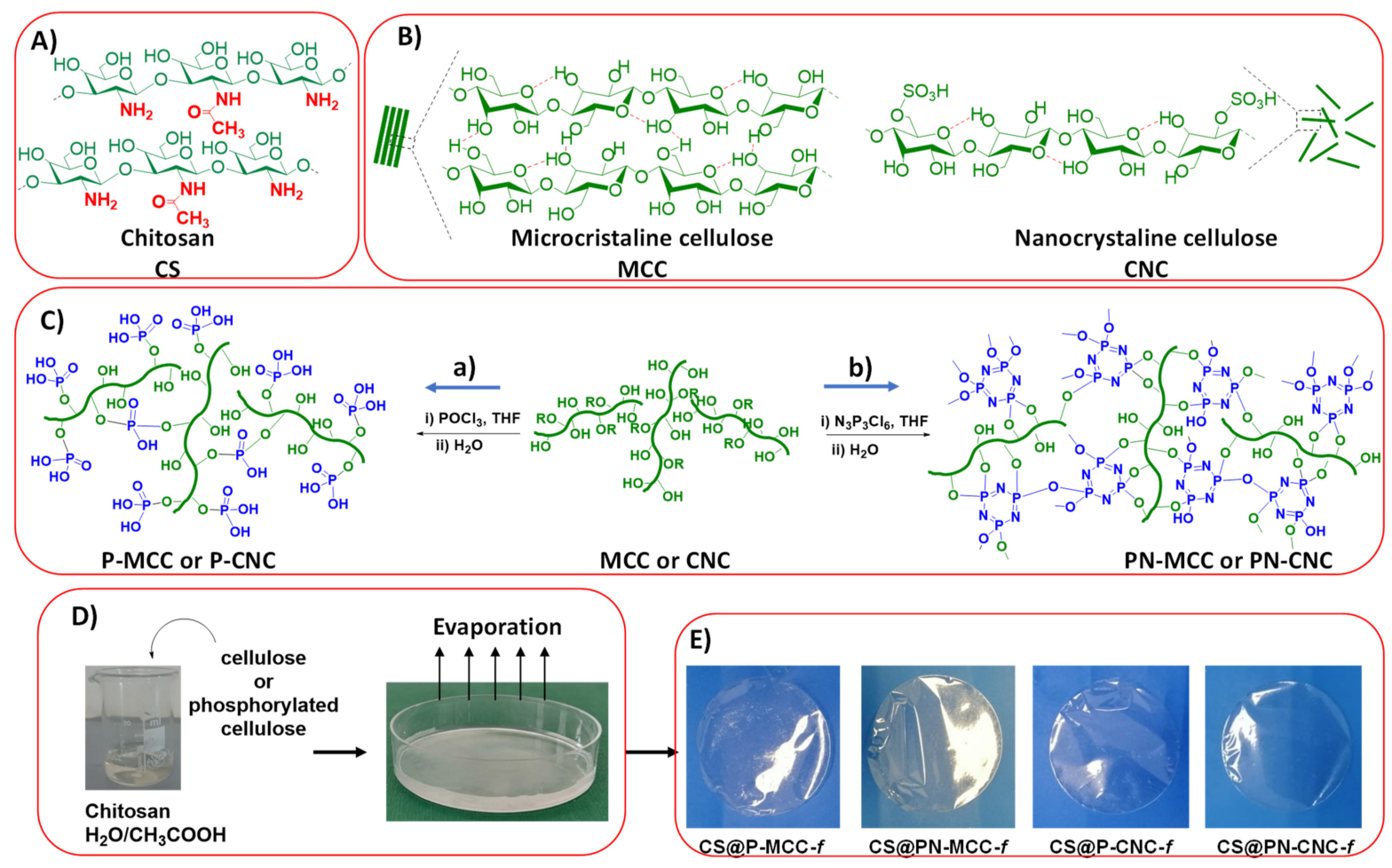

Figure 1. Multistep preparation of cellulose-filled chitosan films. (A) the chemical structure of chitosan used to generate flexible and transparent films; (B) the structure of the two cellulose fillers used to reinforce chitosan, namely microcrystalline cellulose (MCC) with tactoids and isolated tiny crystals of nanocellulose (CNC); (C) the use of two different phosphorylated reagents $\left(\mathrm{POCl}_{3}\right.$ or $\left.\mathrm{N}_{3} \mathrm{P}_{3} \mathrm{Cl}_{6}\right)$ affords two kinds of phosphorylated cellulose (P-MCC/P-CNC and PN-MCC/PN-CNC); (D) mixing of chitosan and cellulose derivative followed by the introduction of the resulting solution in a petri dish and further evaporation of the solvent; (E) digital photos of the resulting cellulose-filled chitosan films, illustrating their transparency. 


\subsection{Hemostatic Properties}

The first stage was done to evaluate the influence of cellulose biocomposites on the activation of the extrinsic and the intrinsic pathways of the blood plasma coagulation system. The effects of the biocomposites were determined based on well-known diagnostic biomarkers, i.e., blood clotting times. Prothrombin (PT), thrombin (TT), and the activated partial thromboplastin time (aPTT) were determined after $15 \mathrm{~min}$ of incubation with the tested films. Figure 2 shows that all of these coagulometric parameters were shortened compared with control blood plasma, which indicated that the composites accelerated blood coagulation.
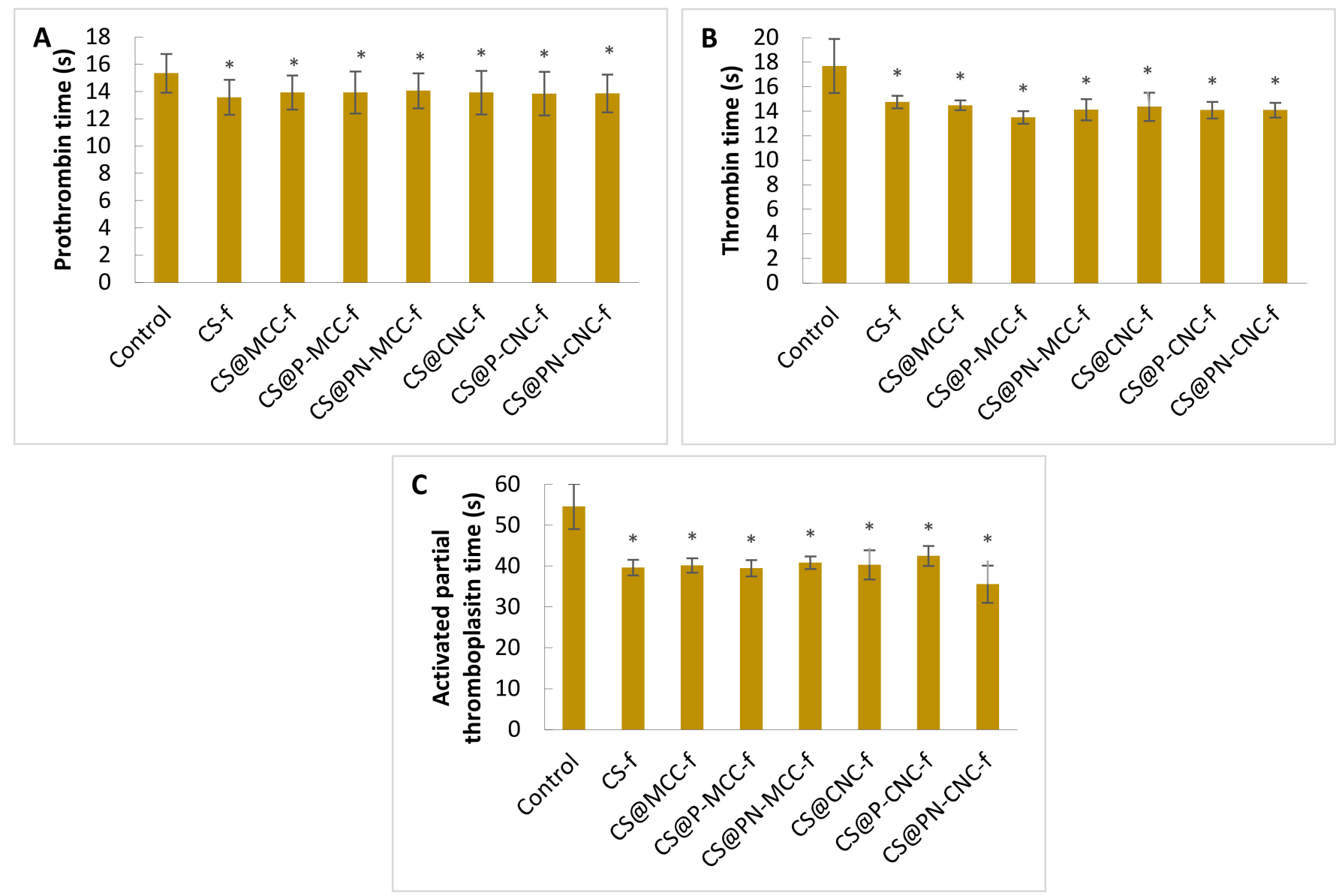

Figure 2. PT (A), TT (B), and aPTT (C) blood clotting times of control human blood plasma incubated with chitosan-cellulose biocomposites. $n=10,{ }^{*} p<0.05$.

Data on prothrombin times after incubation with cellulose films are provided in Figure 2A. The control plasma samples (i.e., blood plasma untreated with biocomposites) coagulated after $15.3 \pm 1.4 \mathrm{~s}$. All biocomposites reduced the time similarly to 14-13 s. Figure 2B shows thrombin times. For the control sample, the time was $17.7 \pm 2.2 \mathrm{~s}$. Incubation with biocomposites reduced this by $\sim 4 \mathrm{~s}$. The most efficient procoagulant activity in the TT measurements occurred in samples incubated with CS@P-MCC-f. Another time measured was the aPTT, which indicated the activity of the intrinsic coagulation pathway. The control took $54.6 \pm 5.5 \mathrm{~s}$, and the incubation of plasma with biocomposites significantly shortened the clot formation time (Figure 2C). The highest level of clotting activity occurred with the CS@PN-CNC-f composite, for which the aPTT time was $35.6 \pm 4.5 \mathrm{~s}$. Similar results were found by $\mathrm{Li}$ et al. [35] who tested the influence of collagen with oxidized microcrystalline cellulose on hemostatic properties. aPTT and TT of sponge collagens with $0.25 \%$ cellulose (M2) had the lowest levels among the materials tested, being significantly 
reduced compared to the normal saline group. The results show that a cellulose supplement can shorten the aPTT time and activate blood plasma clotting factors (VIII, IX and XI and XII), which corresponds to M2 promoting factor XII activation. The data also imply that M2 has a direct impact on the intrinsic coagulation pathway but not on the extrinsic pathway. A reduction in TT indicated that the conversion of plasma fibrinogen into a fibrin clot in the samples of the M2 group was significantly increased compared with the control group. In summary, the addition of cellulose to the tested material could be directly involved in stimulating the intrinsic coagulation pathway, thereby accelerating blood plasma clotting.

Cheng et al. [36] studied the hemostatic mechanism for oxidized microcrystalline cellulose and its composites. They showed that ORC (Oxidized Regenerated Cellulose), OMCC (Oxidized Microcrystalline Cellulose), and the hemostatic composite affected the activation of coagulation factors VIII, IX, XI, XII but did not affect factors III and VII, suggesting that only the intrinsic blood coagulation pathway was activated. This activity can significantly accelerate the activation of blood coagulation factor XII and promote the generation of thrombin [37]. In the presence of thrombin, soluble fibrinogen polymerizes and turns into a fibrin clot. The formation of a fibrin network on the surface of the damaged blood vessel wall is crucial for filling the injury, stopping bleeding, and modulating the activity of the coagulation and fibrinolytic proteins as well as stimulating wound healing [38]. As in the case of the tested cellulosic biomaterials, this investigation focused on a sponge based on large, mesoporous silica nanoparticles (MSN) and N-alkylated chitosan (AC) [39]. aPTT was significantly shortened by MSN, MSN-GACS (mesoporous silica nanoparticles with a glycerol-modified $\mathrm{N}$-alkylated chitosan sponge), and kaolin, whereas AC had no influence on aPTT. In addition, the PT of all of these agents was unchanged, indicating that MSN-GACS does not significantly affect the extrinsic coagulation pathway. $\mathrm{SiO}_{2}$ and kaolin can induce activation of the intrinsic coagulation pathway by activating plasma coagulation factor XII. Therefore, the results suggest that the MSNs in MSN-GACS, rather than $\mathrm{AC}$, freely contact the blood components and activate the intrinsic pathway. The coagulation potential of AC could depend on its positive charge, which can be adsorbed on the cytomembranes of blood cells and by some proteins [40].

\subsection{Measurement of the Total Antioxidant Capacity}

The antioxidant capacity of chitosan-cellulose biocomposites was analyzed on the basis of ABTS's radical scavenging capacity, as shown in Figure 3 [41,42].

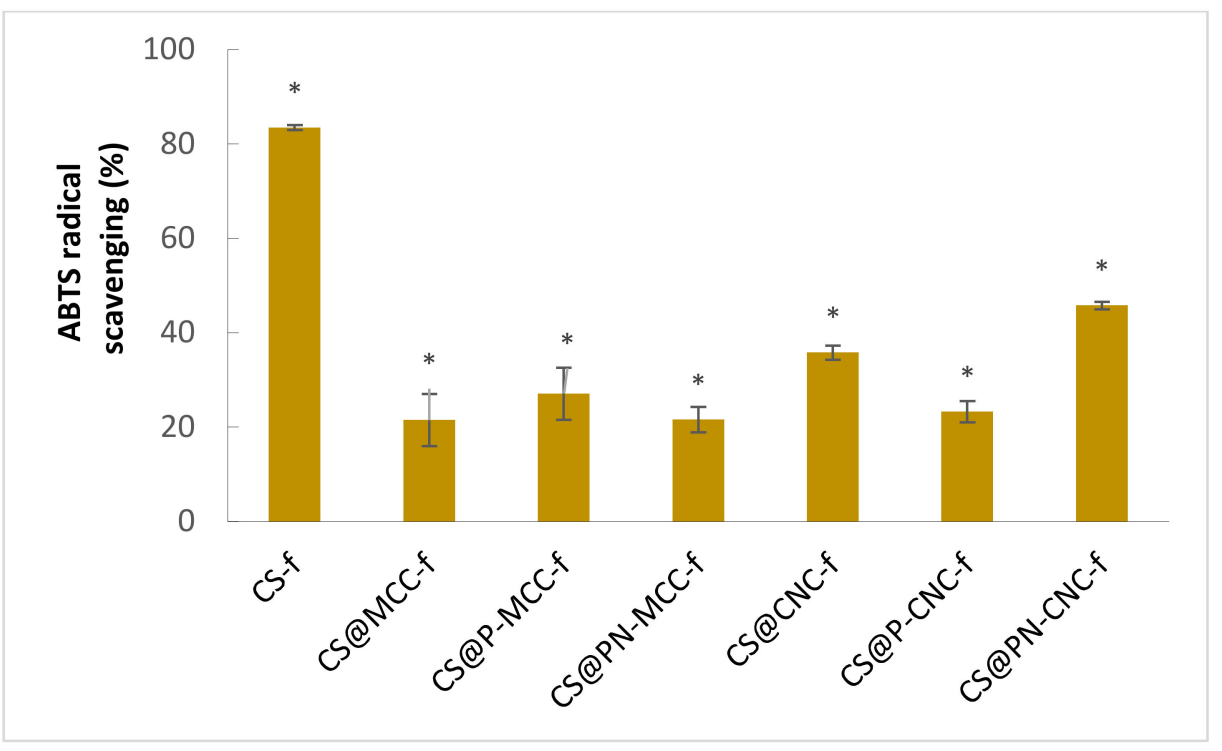

Figure 3. Antioxidant properties of chitosan-cellulose biomaterials after $15 \mathrm{~min}$ of incubation, expressed as a percentage of inhibition, $n=6,{ }^{*} p<0.05$. 
All nanocomposites tested were found to have antioxidant properties after $15 \mathrm{~min}$ of incubation. The nanocomposite with the highest ABTS radical scavenging capacity was the best antioxidant. In the case of the films, free radicals were most effectively removed by the chitosan film, where the scavenging capacity was $83.5 \%$. Nanocomposites containing cellulose in their structure also show antioxidant activity; however, the radical scavenging values were lower compared with CS-f. Nanocomposites reinforced with phosphorylated micro- and nanocellulose (CS@P-MCC-f and CS@PN-MCC-f) were found to have similar antioxidant properties to the nanocomposite without modification, CS@MCC-f. The results are consistent with those presented in other reports, suggesting that cellulose has antioxidant properties [43]. Materials containing nanocellulose have greater antioxidant capacity than those containing microcrystalline cellulose. The highest value for CS@PNCNC-f was $46 \%$. These results suggest that adding cellulose to chitosan may partially reduce its antioxidant properties. Others have tested the antioxidant properties of different cellulose-containing composites. Zhang et al. [44] showed that cellulose nanocrystals (CNC) and cellulose nanofiber (CNF) are excellent controlled release agents and stabilizers that significantly increase the antioxidant and antibacterial properties of edible food-packaging films. Others have also shown antioxidant properties of composites containing cellulose; however, they were often increased by adding other substances, e.g., Rosemary and Aloe Vera essential oils, which contain polyphenols [45] or melanin nanoparticles [46].

\subsection{Cell Viability}

The cytotoxicity of cellulose-filled-chitosan biocomposites was assessed by cell viability studies using BJ and KERTr cell lines after $24 \mathrm{~h}$ of incubation with biocomposites. Cell viability was assessed with the MTT assay. The percentages of viable cells are given relative to control cells incubated without biomaterials (the control being taken as $100 \%$ ) in Figure 4. All of our tested composites, except for CS-f, showed statistically significantly decreased viability for both cell lines. However, the viability of the cells was not $<70 \%$. The decrease in viability depended on the composition of composites and the type of cells. Keratinocytes were more sensitive than fibroblasts (Figure 4). The biggest decrease in KERTr viability was found with the three microcrystalline cellulose composites. For CS@MCC-f, CS@P-MCC-f and CS@PN-MCC-f, the viabilities ranged from 70 to $72 \%$. The least toxic were the CS@CNC-f and CS-f composites, which reduced viability by $\sim 15 \%$. For fibroblasts, the most toxic film (CS@P-CNC-f) decreased viability to $\sim 76 \%$. In contrast, the viability of BJ treated with CS-f remained at the control level (Figure 4A).
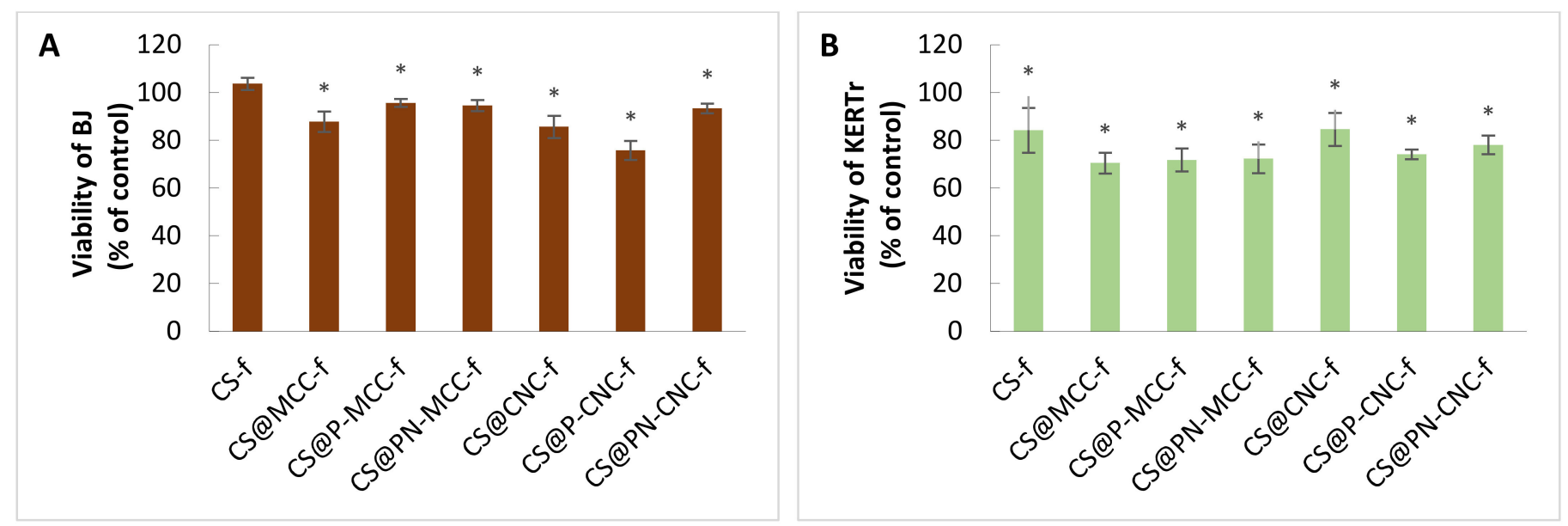

Figure 4. Viability of BJ (A) and KERTr (B) treated with chitosan-cellulose biocomposites for a 24 h incubation period, $n=6$. ${ }^{*} p<0.05$.

There is information on the cytotoxicity of biomaterials containing nanocellulose. Bionanocomposites that do not decrease viability below $80 \%$ can be considered noncytotoxic. 
Poonguzhali et al. [47] assessed the effect of chitosan-PVP-nanocellulose composites on fibroblasts (NIH-3T3). All of the composites decreased in viability to $40-70 \%$ after $24 \mathrm{~h}$ of incubation and to $60-80 \%$ after 3 and 5 days. An increase in viability proved the good compatibility of the composites, because after 3 and 5 days, the cells began to proliferate. Naseri et al. [48] used porous nanocomposite electrospun mats based on chitosan-cellulose nanocrystals for wound healing. The in vitro cytocompatibility of cellulose nanocrystals and electrospun mats $\left(\mathrm{MCNC}_{\mathrm{HCl}}\right.$ and $\left.\mathrm{XMCNC}_{\mathrm{HCl}}\right)$ was measured in a direct contact system using adipose-derived stem cells (ASC) and the L929 cell line. The biomaterials were stained with MTT. Cells in contact with all of their materials had similar morphologies to the negative (non-cytotoxic) control. There was no zone of cell growth inhibition; therefore, the biomaterials were considered noncytotoxic. Some previous studies also showed no cytotoxicity for nanocellulose and nanochitin [49-51].

In our study, the slight decrease in metabolic activity compared with the control was probably unrelated to cell death; the decrease could have been related to decreased cell proliferation. One possible explanation for the decreased proliferation may have been increased mechanical stress caused by polysaccharides, which could have affected the proliferative capacity of other cell types in 3D matrices [52]. A bigger reduction in metabolic activity by keratinocytes may indicate that these types of cells are more sensitive than fibroblasts, consistent with the findings of Burd et al. [53]. Similar results were shown by Čolić et al. [54]. CNF (cellulose nanofibrils) material was noncytotoxic to keratinocytes. The cells retained the same morphology as the control cells, indicating the suitability of CNF as a wound dressing material They also showed reduced metabolic activity and cell proliferation but low cytotoxicity from CNF. Cellulose materials have previously been shown to reduce cell proliferation without affecting the viability of keratinocytes [55]. CNF $(50 \mu \mathrm{g} / \mathrm{mL})$ did not affect fibroblasts or keratinocytes over a $24 \mathrm{~h}$ incubation period, showing that the potential leakage of CNFs in a wound could be acceptable [56].

\subsection{Generation of Reactive Oxygen Species}

To check whether reactive oxygen species (ROS) reduce the viability or proliferative capacities of BJ and KERTr cells, their level was determined after $24 \mathrm{~h}$ of incubation with our tested materials, the results being related to the control (100\%). Only one of the tested films (SC@P-MCC-f) significantly increased the level of ROS in BJ cells. The other tested films did not significantly affect ROS in cells or might have reduce their concentration in some cases (Figure 5). Regarding fibroblasts (Figure 5A), the most significant decrease in ROS occurred in samples incubated with CS@P-CNC-f and CS@CNC-f.
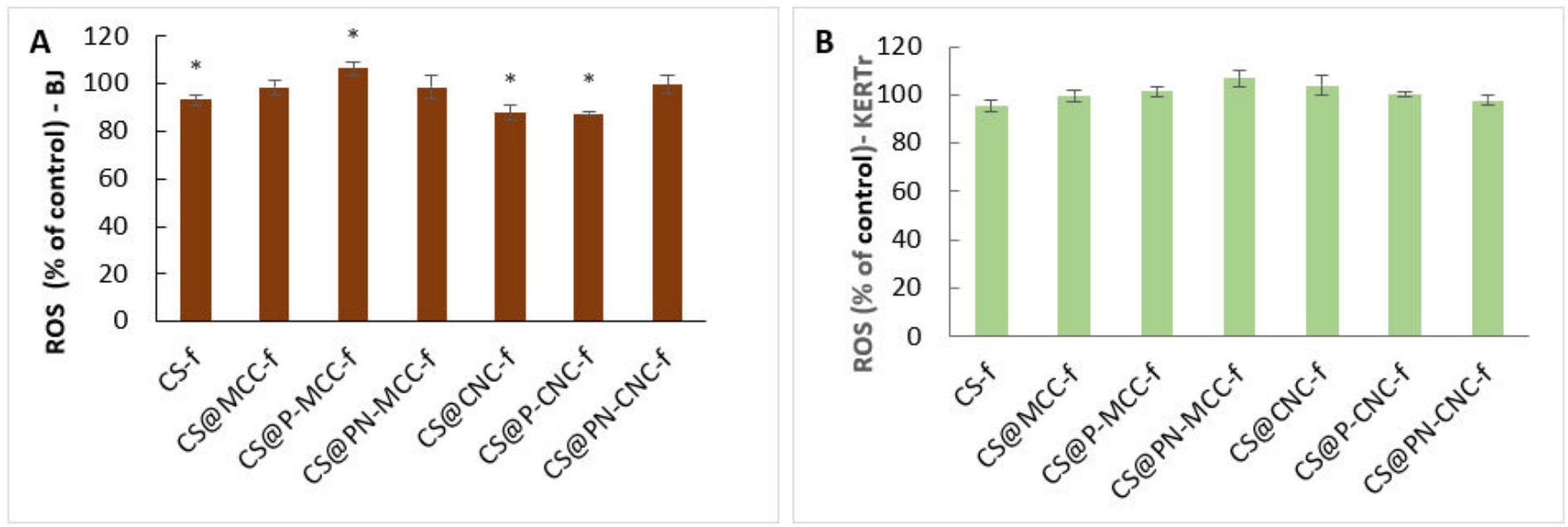

Figure 5. The content of reactive oxygen species in cells of BJ (A) and KERTr (B) incubated for $24 \mathrm{~h}$ with chitosan-cellulose biocomposites, $n=6$. ${ }^{*} p<0.05$. 
Similar results were obtained for modified cellulose nanofibrillation by Aimonen et al. [57], who investigated whether wood-derived nanofibrillated cellulose (NFC) induces intracellular ROS production. Only U-NFC (unmodified) induced a significant increase in ROS formation compared to the negative control at $500 \mu \mathrm{g} / \mathrm{mL}$ after $24 \mathrm{~h}$ of exposure, whereas C-NFC (carboxymethylated), H-NFC (hydroxypropyltrimethylammonium), PNFC (phosphorylated), and S-NFC (sulphoethylated) did not significantly increase the level of ROS for any doses or exposure times.

\subsection{Assessment of Mitochondrial Membrane Potential ( $\Delta \Psi m)$}

Alterations to the mitochondrial membrane potential $(\Delta \Psi \mathrm{m})$ after incubation with chitosan-cellulose biocomposites were monitored using a JC-1 fluorescent probe technique. Experiments on our two cell lines, BJ and KERTr, showed that unmodified chitosan film (CS-f) slightly, but significantly, increased $\Delta \Psi \mathrm{m}$, which suggests that the film does not affect proapoptotic activity (Figure 6). On the other hand, chitosan-cellulose films did not change $\Delta \Psi \mathrm{m}$, or some of them just gave slightly lower potentials. For fibroblasts incubated with CS@P-MCC-f, the lowest value was $90 \%$ of the control value, and for keratinocytes, the biggest decrease was with the CS@CNC-f composite, $\triangle \Psi \mathrm{m}(88 \%)$.
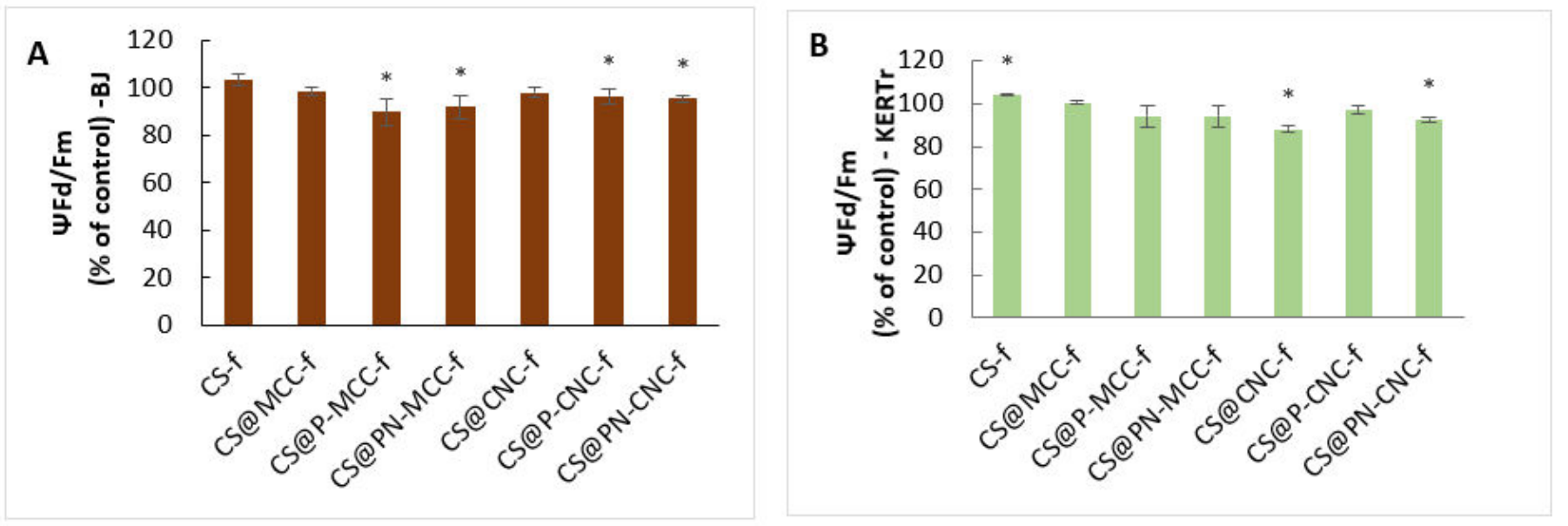

Figure 6. The transmembrane mitochondrial potential $(\triangle \Psi \mathrm{m})$ of $\mathrm{BJ}(\mathrm{A})$ and KERTr $(\mathbf{B})$ incubated for $24 \mathrm{~h}$ with chitosancellulose biocomposites, $n=6 .{ }^{*} p<0.05$.

As suggested by others, biomaterials containing modified forms of cellulose may lower the $\Delta \Psi \mathrm{m}$ by generating mitochondrial ROS [58-60]. Sunasee et al. [61] showed that the cationic nanocrystalline cellulose (CNCs) derivative induces NLRP3 inflammasomedependent IL-1 $\beta$ secretion associated with mitochondrial ROS production. CNC-AEMA2 (aminoethylmethacrylamide) was associated with the biggest loss in $\Delta \Psi \mathrm{m}$, indicating a decrease in the red/green ratio compared with untreated cells. Depolarization of the mitochondrial membrane can directly impact ATP production by mitochondria. Therefore, intracellular and extracellular levels of ATP were also measured. Both CNC-AEMA1 and CNC-AEMA2 decreased intracellular ATP in J774A1 (mouse macrophage) cells; however, CNC-AEMA2 gave a more pronounced negative effect than CNC-AEMA1, as reflected by a significant increase in the extracellular ATP content.

We found a relationship between the $\Delta \Psi \mathrm{m}$ and ROS results for CS@P-MCC-f. This film gave the highest increase in ROS inside BJ cells and led to the largest decrease in $\Delta \Psi \mathrm{m}$, which explains the mechanism of cell membrane depolarization, as the production of intracellular reactive oxygen species interferes with cellular ATP levels, thereby reducing the mitochondrial potential $[62,63]$. 


\subsection{Migration of Fibroblasts and Keratinocytes}

Another important aspect is the influence of chitosan-cellulose composites on the migration process of BJ and KERTr cells. The ability of keratinocytes and fibroblasts to migrate to the wound environment from adjacent areas also determines the success of the healing process. The level of cell migration was determined by the migration assay using ThinCertTM (Figure 7). Among the biomaterials analyzed, CS@CNC-f and CS@MCC-f most strongly increased fibroblast migration after $24 \mathrm{~h}$ of incubation. These composites increased cell migration by one and a half times compared with untreated cells. Composite CS@PN-CNC-f had the smallest influence on the migration of fibroblasts. In the case of keratinocytes, migration was lower than with fibroblasts. The highest level of keratinocytes migrated in samples treated with CS@MCC-f was similar to fibroblasts, but the value was lower, $126 \%$. Interestingly, one of the CS@PN-CNC-f films delayed the migration of keratinocytes compared with the control. It can be concluded that both the microcrystalline and nanocrystalline forms of cellulose have positive effects on migration; however, modification with P- (phosphorylated) and PN- (cyclotriphosphazene) groups reduce the migration effect. Wang et. al. [64] investigated whether bacterial cellulose (BC)/gelatin membranes with electric field stimulation affect cell migration, thereby accelerating wound healing. In particular, a $40 \%$ stretched $\mathrm{BC} /$ gelatin membrane promoted the adhesion, orientation, and migration of NIH3T3 cells. The aligned BC/gelatin membrane synergistically directed the migration of NIH3T3 cells and significantly improved wound healing by accelerating wound closure, increasing the granulation thickness, collagen deposition, and angiogenesis. These findings suggest that a combination of $40 \%$ stretched $\mathrm{BC} /$ gelatin with electric field stimulation may be a promising therapeutic strategy to guide cell migration for improving wound healing.
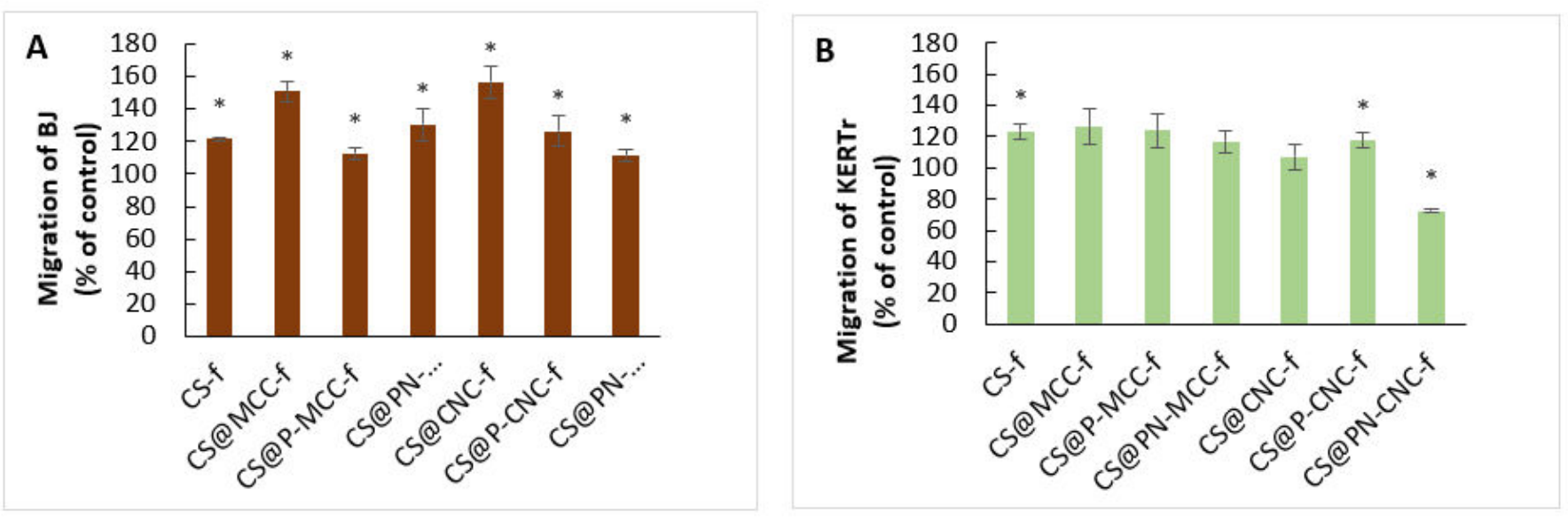

Figure 7. The migration of BJ (A) and KERTr (B) cells incubated for $24 \mathrm{~h}$ with chitosan-cellulose biocomposites, $n=6$, ${ }^{*} p<0.05$.

Research by Bacakova et al. [65] aimed to improve a clinically used carboxymethylcellulose (Hcel ${ }^{\circledR} \mathrm{NaT}$ ) wound dressing by coating it with fibrin and pre-seeding it with skin fibroblasts to create a cell carrier with the potential to deliver skin cells to a wound. This novel cell-enriched dressing is expected to improve the healing capacity of deep wounds. After degradation of the fibrin coating by cells, their cellulose scaffolds would become less attractive than the wound bed for cell adhesion, and thus, spontaneous release and migration of cells from these scaffolds could be expected. The scaffolding could then be easily removed, and thus scaffolds based on fibrin-modified cellulose can serve as cell carriers for skin wounds. A similar phenomenon was seen with human keratinocytes grown on poly-(2-hydroxyethyl methacrylate) plates used clinically to treat severe burns [66]. 


\subsection{Genotoxicity}

For testing materials that may have potential use in medicine, it is important to check their activities from different aspects, notably their genotoxicity. For this purpose, the comet test was used, which gives an answer to whether composites induce single- or double-stranded DNA breaks. Genotoxicity of materials may result from direct interactions with DNA or from an indirect response induced by several factors, including surface stress, through the direct influence of particles on DNA, the release of toxic ions from soluble nanoparticles, or the generation of oxidative stress [67-69]. The percentage of DNA in the tail is used to describe damage in the test specimens. The results shown in Figure 8A,B concern the DNA content in the tails of fibroblasts and keratinocytes, respectively, after 24 $\mathrm{h}$ of incubation with chitosan-cellulose biocomposites. Negative controls were untreated cells, and positive controls were cells treated with $\mathrm{H}_{2} \mathrm{O}_{2}$. All films significantly increased the tail moment. The greatest tail moment was found for cells treated with CS@P-MCC-f. CS@P-MCC-f also slightly increased the level of ROS, which might have caused oxidative stress and led to DNA damage. However, these changes did not exceed $10 \%$, so it can be concluded that the tested films are non-genotoxic. Genotoxicity measurements of cellulosecontaining biocomposites were carried out by Coelho et al. [70], who checked the toxicity of bacterial cellulose membranes functionalized with hydroxyapatite and the antibone morphogenetic protein 2 (BC-HA) on a murine osteoblast line, MC3T3. The percentage of DNA in the tail determined using the Comet Assay revealed that BC-HA is non-genotoxic compared with its negative control (NC); the percentage of DNA in the tail was found to be approximately $3 \%$. They also tested the toxicity of therapeutic contact lenses based on bacterial cellulose with coatings to provide transparency. The assessment showed genotoxicity in only one case, but this was due to diclofenac sodium. None of the lenses tested had a mutagenic effect [71]. Moreira et al. [72] also confirmed that cellulose is nongenotoxic; they concluded from the comet test that cellulose nanofibers (NFs) do not induce DNA strand breaks or crosslinks.
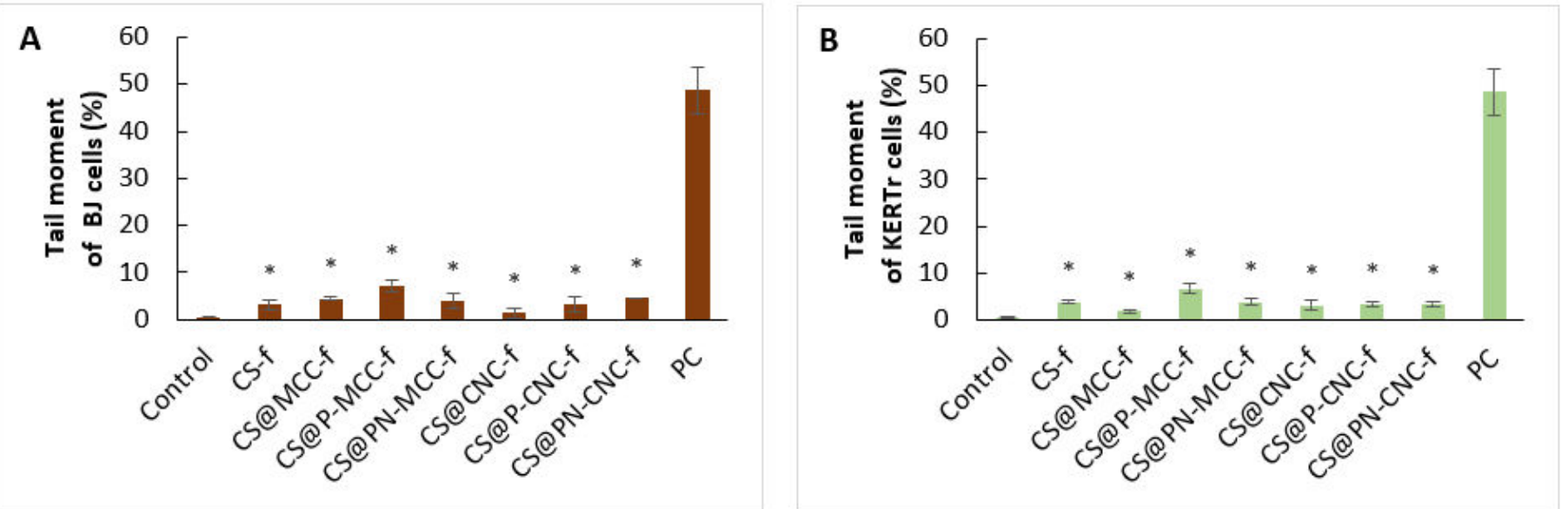

Figure 8. The genotoxicity of BJ (A), KERTr (B) cells incubated for $24 \mathrm{~h}$ with chitosan-cellulose biocomposites, $n=6$, ${ }^{*} p<0.05$.

\section{Materials and Methods}

\subsection{Materials}

Cellulose-filled chitosan nanostructured films were prepared in accordance with previously described procedures [33]. The commercially available reagents and solvents phosphoryl chloride, hexachlorotricyclophosphazene, ethanol $(99.8 \%)$, tetrahydrofuran $(97 \%)$, and acetic acid $(98 \%)$ were purchased from Across and Sigma-Aldrich (St. Louis, MO, USA). Chitosan (190-310 kDa) and 85\% deacetylation degree were purchased from Sigma-Aldrich (Hamburg, Germany). Phosphate-buffered saline (PBS) was purchased from BioShop (Burlington, ON, Canada). Glutaraldehyde 25\% and osmium tetroxide 
4\% solution were purchased from Agar Scientific (Stansted, UK). Absolute ethanol was purchased from EMSURE (Darmstadt, Germany). Microcrystalline cellulose (MCC, CAS 9004-34-6) synthesized from cotton linters was purchased from Sigma-Aldrich. Cotton wool used for the synthesis of nanocellulose was purchased from Fisher Scientific (Hampton, $\mathrm{NH}, \mathrm{USA}$ ). Ultrasonication involved a VWR ultrasonic cleaner (USC-THD: Power 9 VWR International $\mathrm{GmbH}$, Vienna, Austria).

The human fibroblast BJ (CRL-2522) cell line and human keratinocyte CCD 1102 KERTr (CRL-2310) were purchased from American Type Culture Collection ATCC ${ }^{\circledR}$ (Manassas, VA, USA). Keratinocyte serum-free medium with added keratinocyte supplements, including bovine pituitary extract (BPE), human recombinant epidermal growth factor (EGF), fetal bovine serum (FBS), and Dulbecco's modified Eagle's medium (DMEM), was purchased from Gibco, Thermo Fisher Scientific (Waltham, MA, USA). Blood from healthy donors was obtained from the Regional Blood Donation and Blood Treatment Center in Lodz, Poland. Dimethyl sulfoxide (DMSO) 3-(4,5-2-yl)-2-5-diphenyl tetrazolium bromide (MTT), 5',6,6'-tetrachloro-1,1',3,3'-tetraethyl-imidacarbocyanine iodide (JC-1), 2,7-dichlorodihydrofluorescin diacetate ( $\left.\mathrm{H}_{2} \mathrm{DCFDA}\right), 2,2^{\prime}$-azinobis(3-ethylbenzothiazoline6-sulfonic acid) diammonium salt (ABTS), potassium persulfate (di-potassium peroxdisulfate), phosphate buffered saline (PBS) tablets, fetal bovine serum, and trypsin were purchased from Sigma-Aldrich (Saint Louis, MO, USA). Commercially available reagents for the determination of clotting times (Dia-PT and DiaPTT) were purchased from Diagon (Budapest, Hungary). The thrombin enzyme was provided by Biomed (Lublin, Poland).

Fresh human blood plasma for hemostatic assays derived from buffy coats (from healthy volunteers) was purchased from the Regional Centre of Blood Donation and Blood Treatment in Lodz (Poland).

The genotoxicity study used a fluorescent dye that strongly binds to DNA by DAPI intercalation (Gibco, Thermo Fisher Scientific, Waltham, MA, USA). Membrane culture inserts for 24-well plates, PET, and $8 \mu \mathrm{M}$ pores to check cell migration were purchased from Biokom (Janki, Poland).

All other chemicals used were of analytical grade, and solutions were prepared using water purified by the Mili-Q system.

\subsection{Measurements of Prothrombin Time (PT)}

Activation of the extrinsic and intrinsic pathways of blood coagulation [73] was determined using the Optic Coagulation Analyzer K-3002 (KSELMED, Grudziadz, Poland) $[74,75]$. In measurements of the PT, human plasma $(1.5 \mathrm{~mL})$ was incubated with cellulose films in the form of squares $(0.5 \times 0.5 \mathrm{~cm})$ for $15 \mathrm{~min}$ at $37^{\circ} \mathrm{C}$ and then sampled in a $50 \mu \mathrm{L}$ coagulometric cuvette with $50 \mu \mathrm{L}$ thromboplastin (i.e., Dia-PT reagent; DIAGON, Budapest, Hungary; a commercial preparation was dissolved in $2 \mathrm{~mL}$ deionized water) and incubated for $1 \mathrm{~min}$ at $37^{\circ} \mathrm{C}$ on a block heater. After incubation, the cuvette was transferred to the analyzer, and $50 \mu \mathrm{L}$ of $25 \mathrm{mM} \mathrm{CaCl}_{2}$ was immediately added.

\subsection{Measurements of the Thrombin Time (TT)}

Human plasma $(1.5 \mathrm{~mL})$ was incubated with cellulose biomaterials in the form of squares $(0.5 \times 0.5 \mathrm{~cm})$ for $15 \mathrm{~min}$, sampled into a $50 \mu \mathrm{L}$ measuring cuvette, and incubated for $1 \mathrm{~min}$ at $37^{\circ} \mathrm{C}$ on a block heater. The cuvette was transferred to the measuring holes and $100 \mu \mathrm{L}$ thrombin (Biomed, Lublin, Poland) was added (final concentration $1 \mathrm{U} / \mathrm{mL}$ ). The thrombin time (TT) was determined coagulometrically (Optic Coagulation Analyser K-3002; KSELMED, Grudziadz, Poland).

\subsection{Activated Partial Thromboplastin Time (aPTT)}

Activation of the intrinsic blood coagulation pathway was determined using the Dia-PTT reagent (i.e., cephalin preparation for activated partial thromboplastin time measurements dissolved in $4 \mathrm{~mL}$ deionized water and incubated at $37^{\circ} \mathrm{C}$ for $30 \mathrm{~min}$ ). A cuvette was placed in the coagulometer thermostat (Optic Coagulation Analyzer K-3002; 
KSELMED, Grudziadz, Poland) and $50 \mu \mathrm{L}$ of plasma previously incubated for 15 min with cellulose biocomposites was introduced to it. The dia-PTT reagent was added to the plasma in the cuvette. The mix was incubated at $37^{\circ} \mathrm{C}$ for $3 \mathrm{~min}$. Then, $50 \mu \mathrm{L}$ of $0.025 \mathrm{M} \mathrm{CaCl}_{2}$ was added to the cuvette prior to measurement. Following the addition of $\mathrm{CaCl}_{2}$, further clotting factors were activated, leading to the formation of a blood plasma fibrin clot.

\subsection{Measurement of the Total Antioxidant Capacity}

A colored blue-green solution of the radical ABTS $\left(\mathrm{ABTS}^{\bullet+}\right)$ is formed by the reaction between ABTS and $\mathrm{K}_{2} \mathrm{O}_{8} \mathrm{~S}_{2}$. ABTS and potassium persulfate were dissolved in distilled water to final concentrations of 7 and $2.45 \mathrm{mM}$, respectively. These two solutions were mixed and left to stand in a dark at room temperature for $16 \mathrm{~h}$ before use in order to produce the ABTS radical $\left(\mathrm{ABTS}^{\bullet+}\right.$ ). The absorption spectrum of $\mathrm{ABTS}^{\bullet+}$ is characterized by the presence of several maxima for the wavelengths 415, 645, 734, and $815 \mathrm{~nm}$. Adding an antioxidant to the solution reduces the concentration of the ABTS radical, discoloring the solution [76]. The ABTS radical solution was diluted with distilled water to an absorbance of $0.7-0.9$ at $734 \mathrm{~nm}$. Biocomposites were added to the diluted ABTS ${ }^{\bullet+}$ solution $(1.5 \mathrm{~mL})$ and incubated for $15 \mathrm{~min}$, and the absorbance was read using a spectrophotometer. The percentage of reaction inhibition was calculated from the formula (1):

$$
\text { ABTS radical scavenging }(\%)=\left(1-\mathrm{A} / \mathrm{A}_{0}\right) \times 100 \%
$$

where:

$\mathrm{A}_{0}$-represents the absorbance of the control (only ABTS) at $734 \mathrm{~nm}$

A-represents the absorbance of the sample (ABTS + film) at $734 \mathrm{~nm}$

\subsection{Cell Culture}

Cells were cultured using regular practices. Adherent BJ cells were grown in DMEM growth medium, whereas the KERTr cells were grown in Keratinocyte-Serum Free medium (Gibco). DMEM was supplemented by increased concentrations of vitamins and amino acids, as well as pyruvate and glucose. DMEM was supplemented with $10 \%$ inactivated FBS and an antibiotic (1\% penicillin). Keratinocyte-Serum Free (Gibco) medium was supplemented with Keratinocyte Supplements, including Bovine Pituitary Extract (BPE, Gibco) and human recombinant epidermal growth factor (EGF, Gibco). Both cultures were carried out under standard conditions in a $\mathrm{CO}_{2}$ incubator $\left(37^{\circ} \mathrm{C}, 95 \%\right.$ air and $5 \% \mathrm{CO}_{2}, 100 \%$ relative humidity). Cells of both lines were maintained in the logarithmic growth phase by regular passage into new culture flasks after the cells had reached $\sim 80 \%$ confluence. Monolayers were washed sequentially with an isotonic saline solution $(0.9 \%)$, and the cell monolayers were trypsinized by adding 0.25\% trypsin with EDTA and KERTr by adding a $0.25 \%$ TrypLE solution (Gibco) in the appropriate volumes. Cells were incubated for 3-5 min in a $\mathrm{CO}_{2}$ incubator and checked under a microscope. After detachment, DMEM culture medium was added to BJ and Keratinocyte-Serum Free was added to KERTr, respectively. Cell viability was checked at each passage using Trypan blue, which enters cells with damaged cell membranes, making them blue. A small amount of the cell suspension $(\sim 10 \mu \mathrm{L})$ was mixed 1:1 with Trypan blue and applied to the plates. During measurement, the total cell density and the amount of dead and living cells per $1 \mathrm{~mL}$ of suspension were determined.

\subsection{Cell Viability Assay (MTT Assay)}

The cytotoxicity of chitosan-cellulose films was measured by the MTT assay, which is based on cellular reduction of the soluble yellow dye 3-[4,5-tetrazolium salt) dimethylthiazol-2-yl]-2,5-diphenyltetrazolium bromide (MTT) by mitochondrial dehydrogenases to water-insoluble purple formazan in living cells. Therefore, the amount of formazan crystals is proportional to the number of living cells, because the dehydrogenases are inactive in dead cells $[77,78]$. 
The BJ cells were seeded in flat-bottomed 24-well plates at concentrations of $5 \times 10^{4}$ (BJ) and $10^{5}$ (KERTr) cells in $400 \mu \mathrm{L}$ medium per well. After $24 \mathrm{~h}$, they were treated with films in the form of $0.5 \times 0.5 \mathrm{~cm}$ squares, with the controls being untreated. The plates with biocomposites were incubated for $24 \mathrm{~h}$ under culture conditions before the MTT test was used. The medium was removed from the wells, and the cells were washed twice with PBS $(200 \mu \mathrm{L})$. MTT reagent $(200 \mu \mathrm{L})$ was added to the wells and incubated for $3 \mathrm{~h}$ at $37^{\circ} \mathrm{C}$. MTT was aspirated, and $400 \mu \mathrm{L}$ DMSO was added to each well. The absorbance at $570 \mathrm{~nm}$ was measured spectrophotometrically (BioTek, Synergy HTX multi-mode reader, Winooski, VT, USA). MTT tests were repeated in 6 separate experiments. The percentage of viability was calculated using the formula (2):

$$
\% \text { Viablility }=A_{s} / A_{c} \times 100 \%
$$

where: $A_{s}$ is the absorbance of the sample and $A_{c}$ is the absorbance of the samples control (untreated cells).

\subsection{Generation of Reactive Oxygen Species}

$\mathrm{H}_{2}$ DCFDA is a form of reduced fluorescein that freely penetrates cells, where it is hydrolyzed to its non-fluorescent form, $\mathrm{H}_{2} \mathrm{DCF}$, by intracellular esterases. Subsequently, $\mathrm{H}_{2}$ DCF is oxidized by ROS to $2^{\prime}, 7^{\prime}$-dichlorofluorescein (DCF). DCF is localized in the cytoplasm and is strongly fluorescence, its intensity being proportional to the concentration of ROS [79-81].

BJ cells were seeded in black 96-well plates at $1.25 \times 10^{4}$ per well and KERTr cells at $2.5 \times 10^{4}$ per well. After $24 \mathrm{~h}$ of incubation with the biocomposites, the medium was removed, and the cells were washed with PBS before $50 \mu \mathrm{L} 2 \mu \mathrm{M} \mathrm{H}_{2}$ DCFDA was added. The probe plate incubation time was $15 \mathrm{~min}$. The solution was recovered, and $50 \mu \mathrm{L}$ of PBS was added per well. Samples were analyzed using a Fluoroscan Ascent FL microplate reader (BioTek, Synergy HTX multi-mode reader) with an excitation wavelength of $\lambda_{\mathrm{ex}}=495$ and emission wavelength of $\lambda_{\mathrm{em}}=529$.

\subsection{Assessment of the Mitochondrial Membrane Potential ( $\Delta \Psi m$ )}

One of the parameters that proves mitochondrial dysfunction is a decrease in $\Delta \Psi \mathrm{m}$. The JC-1 probe (5,5-iodide,6,6'-tetrachloro-1,1',3,3'-tetraethylbenzimidazolycarbocyanine) was used to determine $\Delta \Psi \mathrm{m}$. The probe is a positively charged lipophilic fluorescent marker. Normal cells with appropriate potentials ensure more efficient functioning of metabolic pathways, providing the cell with more ATP, so $\Delta \Psi \mathrm{m}$ values range from -120 to $-180 \mathrm{mV}$. In damaged cells, energy production in the form of ATP is decreased, and membrane depolarization - a decrease in the potential—occurs. The primary location for the probe is the mitochondrial matrix. JC- 1 comes in monomer and dimer forms. The dimeric form occurs when the mitochondrial membrane is polarized, with a high $\Delta \Psi \mathrm{m}$. Red fluorescence is then emitted. In the case of the monomeric form, the value of $\Delta \Psi \mathrm{m}$ is lower, and the characteristic fluorescence is green [82].

BJ cells were plated in black 96-well plates at $12.5 \times 10^{3} /$ well and KERTr cells were plated at $25 \times 10^{3}$. After incubation for $24 \mathrm{~h}$ with biocomposites, the medium was removed. After washing with PBS, $50 \mu \mathrm{L}$ of JC-1 $(1 \mu \mathrm{M})$ was added. The plate was incubated for $30 \mathrm{~min}$ in the dark, and the solution was removed from the wells. PBS $(50 \mu \mathrm{L})$ was added to each well and measured. In the analysis, specialized filters were used to measure the fluorescence of monomers $(\lambda \mathrm{ex}=485 \mathrm{~nm}, \lambda \mathrm{em}=538 \mathrm{~nm})$ and dimers $(\lambda \mathrm{ex}=530 \mathrm{~nm}$, $\lambda \mathrm{em}=590 \mathrm{~nm}$ ). From the measurement on a Fluoroscan Ascent FL microplate leader (BioTek, Synergy HTX multi-mode reader), the fluorescence coefficient was calculated (3):

$$
\Psi \mathrm{m}=\mathrm{Fd} / \mathrm{Fm}
$$


where $\Psi \mathrm{m}$ is the transmembrane mitochondrial potential directly proportional to the fluorescence coefficient, Fd is the fluorescence of dimers, and Fm is the fluorescence of monomers.

\subsection{Cell Migration}

$\mathrm{BJ}$ and KERTr cells were starved overnight in serum-free medium with $0.2 \%$ bovine serum albumin (BSA) [83,84]. Harvested BJ cells were washed twice in PBS and resuspended in serum-free DMEM medium with $0.2 \%$ BSA to obtain an appropriate final concentration of $2.5 \times 10^{5}$ cells $/ \mathrm{mL}$, whereas KERTr cells were resuspended in growthfactor-free medium to the same cell density. Twenty-four-well ThinCert ${ }^{\mathrm{TM}}$ cell culture inserts with $8 \mu \mathrm{M}$ pores and translucent PET membranes were placed in the wells of a CELLSTAR $^{\circledR}$ cell culture plate. Six hundred microliters of DMEM medium with $10 \%$ FBS was added to each well of the BJ cell culture plate (lower compartment). For keratinocytes, Keratinocyte-Serum Free medium with growth factors was added to the lower wells. Two hundred microliters of BJ cell suspension with $450 \mu \mathrm{L}$ of free-serum medium DMEM was added to each cell culture insert, and the same volumes of KERTr and free-growth factor medium Keratinocyte-Serum Free were used. The plate with inserts was incubated for $24 \mathrm{~h}$ in an incubator at $37^{\circ} \mathrm{C}$ and $5 \% \mathrm{CO}_{2}$ in air. The culture medium was removed from the ThinCert ${ }^{\mathrm{TM}}$ cell culture inserts, and the inserts were transferred to the wells of a freshly prepared 24-well plate containing $500 \mu \mathrm{L}$ of Trypsin-EDTA per well. This plate was incubated for $10 \mathrm{~min}$ in a cell culture incubator at $37^{\circ} \mathrm{C}$ and $5 \% \mathrm{CO}_{2}$ with sporadic agitation. The inserts were discarded, and $200 \mu \mathrm{L}$ of Trypsin-EDTA solution (now containing the detached migratory cells) was transferred from each well into a new well of a flat-bottom 24-well plate. Finally, the viability of the migrating cells was determined using the MTT test and measured spectrophotometrically at $570 \mathrm{~nm}$.

\subsection{Comet Assay}

The alkaline version of the comet assay was carried out according to the procedure of Singh et al. [85] with slight modifications described by Blasiak and Kowalik [86]. Briefly, $100 \mu \mathrm{L}$ (50,000 cells) of cell suspension was mixed with $10 \mu \mathrm{L}$ of $0.75 \%$ low melting-point agarose (LMP) at $37^{\circ} \mathrm{C}$ and spread on a normal agarose (NMP) pre-coated microscope slide. The slides with cells were covered with a coverslip and subsequently placed on an ice-cold surface to solidify for about $10 \mathrm{~min}$. The coverslips were removed, and the slides were placed in cold lysing solution $(2.5 \mathrm{M} \mathrm{NaCl}, 0.1 \mathrm{M}$ EDTA, $10 \mathrm{mM}$ Tris, $1 \%$ Triton $\mathrm{X}-100,10 \%$ DMSO, pH 10; the last two components were added freshly). Lysis took $1 \mathrm{~h}$ at $4{ }^{\circ} \mathrm{C}$ in the dark. The slides were incubated in an electrophoretic buffer $(300 \mathrm{mM} \mathrm{NaOH}$, $1 \mathrm{mM}$ EDTA, $\mathrm{pH}>13$ ) for $20 \mathrm{~min}$ to allow the unwinding of DNA before electrophoresis. Electrophoresis was run in the same buffer at $0.73 \mathrm{~V} / \mathrm{cm}(28 \mathrm{~mA})$ for $20 \mathrm{~min}$ to allow damaged DNA or fragments to migrate towards the anode. The slides were washed in water, drained, stained with $2 \mu \mathrm{g} / \mathrm{mL}$ DAPI, and covered with coverslips. Microscopic analysis was started after a minimum of $30 \mathrm{~min}$. To prevent additional DNA damage, the whole procedure was conducted under limited light or in the dark. The comets were analyzed by an Eclipse fluorescence microscope (Nikon, Tokyo, Japan) attached to a COHU 4910 video camera (Cohu, Inc., San Diego, CA, USA) equipped with a UV-1 A filter block and connected to a personal computer-based image analysis system Lucia-Comet v. 4.51 (Laboratory Imaging, Praha, Czech Republic). The tail moment, as a measure of DNA damage in the graphic presentation, represents the mean of 50 images (comets) randomly selected from each sample of 3 individual experiments.

\subsection{Statistical Analysis}

Data are presented as the mean \pm SD from a minimum of 3 sets of measurements. Statistical differences between the control and treatment groups were analyzed by one-way ANOVA followed by Tukey's analysis. $p<0.05$ was taken as statistically significant. 


\section{Conclusions}

While the use of marine polysaccharides for wound healing has been intensely investigated, few reports have focused on deciphering the role of the filler used to reinforce the polysaccharide matrix in accelerating or delaying wound healing. We have consequently designed several nanocomposite films built from chitosan marine waste. The common threat with these materials is the use of cellulose as a filler. The use of icrometric versus nanometric cellulose and phosphorylated versus non-modified cellulose enabled the preparation of seven films. Our investigation allowed a comparative performance relationship based on the size of the filler and the functionalization type. Measurements of the hemostatic, cytotoxic, and genotoxic properties of cellulose-filled-chitosan films showed that these nanocomposites shorten the clotting times by affecting both the extrinsic and intrinsic coagulation systems and have antioxidant properties. They only slightly reduced the viability of human skin cells and were not genotoxic. In addition, most of the tested nanocomposites significantly accelerated the migration of both fibroblasts and keratinocytes, which is very important since increased skin cell migration promotes wound healing and accelerates scarring. Associated with the previously demonstrated antibacterial properties of phosphorylated cellulose-filled chitosan films, the results shown herein suggest that these transparent, fully degradable, and biocompatible nanocomposite films have the potential to be implemented in wound dressing devices.

Author Contributions: Conceptualization, M.K. and K.M.; methodology, M.K. and K.M.; software, M.K. and K.M.; investigation, M.K.; resources, K.M. and A.E.K.; preparation and characterization of functional cellulose films S.B., N.K. and M.L. writing-original draft preparation, M.K.; writingreview and editing, M.K., K.M., J.K.-C., A.E.K., M.B. supervision, K.M.; funding acquisition, K.M. and M.B.; analysis M.K and K.M. All authors have read and agreed to the published version of the manuscript.

Funding: This research was funded in part by (PHC 19/87) (CNRST-CNRS) and Projet Prioritaire (PPR1/2015/73).

Institutional Review Board Statement: Not applicable.

Informed Consent Statement: Not applicable.

Data Availability Statement: Not applicable.

Acknowledgments: This research was funded in part by (PHC 19/87) (CNRST-CNRS) and Projet Prioritaire (PPR1/2015/73). A.E.K. thanks also UEMF and Académie Hassan II des Sciences et Technique for funding the Nano-Bio-Mat project.

Conflicts of Interest: The authors declare no conflict of interest.

\section{References}

1. Atala, A.; Lanza, R.; Thomson, J.A.; Nerem, R. Principles of Regenerative Medicine; Elsevier: New York, NY, USA, 2011.

2. Lanza, R.; Langer, R.; Vacanti, J. Principles of Tissue Engineering; Elsevier: Burlington, MA, USA, 2007; pp. $421-429$.

3. Roubelakis, M.G.; Trohatou, O.; Roubelakis, A.; Mili, E.; Kalaitzopoulos, I.; Papazoglou, G.; Pappa, K.I.; Anagnou, N.P. Plateletrich plasma (PRP) promotes fetal mesenchymal stem/stromal cell migration and wound healing process. Stem Cell Rev. 2014, 10, 417-428. [CrossRef]

4. Kalinin, A.E.; Kajava, A.V.; Steinert, P.M. Epithelial barrier function: Assembly and structural features of the cornified cell envelope. Bioessays 2002, 24, 789-800. [CrossRef]

5. Martin, P. Wound healing-Aiming for perfect skin regeneration. Science 1997, 276, 75-81. [CrossRef] [PubMed]

6. Wild, T.; Rahbarnia, A.; Kellner, M.; Sobotka, L.; Eberlein, T. Basics in nutrition and wound healing. Nutrition 2010, $26,862-866$. [CrossRef] [PubMed]

7. Forrest, R.D. Early history of wound treatment. J. R. Soc. Med. 1982, 75, 198-205. [PubMed]

8. Harris, T.R.; Bransford, J.D.; Brophy, S.P. Roles for learning sciences and learning technologies in biomedical engineering education: A review of recent advances. Annu. Rev. Biomed. Eng. 2002, 4, 29-48. [CrossRef]

9. Pittman, J. Effect of aging on wound healing: Current concepts. J. Wound Ostomy Cont. Nurs. 2007, 34, 412-417. [CrossRef]

10. Pikuła, M.; Langa, P.; Kosikowska, P.; Trzonkowski, P. Komórki macierzyste i czynniki wzrostu w gojeniu ran. Postepy Hig. Med. Dosw. 2015, 69, 874-885. [CrossRef] [PubMed]

11. Loeb, L. A comparative study of the mechanism of wound healing. J. Med. Res. 1920, 41, 247-281. 
12. Opneja, A.; Kapoor, S.; Stavrou, E.X. Contribution of platelets, the coagulation and fibrinolytic systems to cutaneous wound healing. Thromb. Res. 2019, 179, 56-63. [CrossRef] [PubMed]

13. Andrea, J.; Gallini, R.; Betsholtz, C. Role of platelet-derived growth factors in physiology and medicine. Genes Dev. 2008, 22, 1276-1312. [CrossRef] [PubMed]

14. Balakrishnan, B.; Mohanty, M.; Umashankar, P.R.; Jayakrishnan, A. Evaluation of an in situ forming hydrogel wound dressing based on oxidized alginate and gelatin. Biomaterials 2005, 26, 6335-6342. [CrossRef] [PubMed]

15. Lau, K.; Paus, R.; Tiede, S.; Day, P.; Bayat, A. Exploring the role of stem cells in cutaneous wound healing. Exp. Dermatol. 2009, 18, 921-933. [CrossRef] [PubMed]

16. Peplow, P.V.; Chatterjee, M.P. A review of the influence of growth factors and cytokines in in vitro human keratinocyte migration. Cytokine 2013, 62, 1-21. [CrossRef] [PubMed]

17. $\mathrm{Hu}, \mathrm{H}$; $\mathrm{Xu}, \mathrm{F} . J$. Rational design and latest advances of polysaccharide-based hydrogels for wound healing. Biomater. Sci. 2020, 8 , 2084-2101. [CrossRef]

18. Cheng, H.; Li, C.; Jiang, Y.; Wang, B.; Wang, F.; Mao, Z.; Xu, H.; Wang, L.; Sui, X. Facile preparation of polysaccharide-based sponges and their potential application in wound dressing. J. Mater. Chem. B. 2018, 6, 634-640. [CrossRef]

19. Jing, X.; Sun, Y.; Ma, X.; Hu, H. Marine polysaccharides: Green and recyclable resources as wound dressings. Mater. Chem. Front. 2021, 5, 5595-5616. [CrossRef]

20. Liang, Y.; He, J.; Guo, B. Functional Hydrogels as Wound Dressing to Enhance Wound Healing. ACS Nano 2021, 15, 12687-12722. [CrossRef]

21. Zhong, Y.; Xiao, H.; Seidi, F.; Jin, Y. Natural Polymer-Based Antimicrobial Hydrogels without Synthetic Antibiotics as Wound Dressings. Biomacromolecules 2020, 21, 2983-3006. [CrossRef]

22. Rial-Hermida, M.I.; Rey-Rico, A.; Blanco-Fernandez, B.; Carballo-Pedrares, N.; Byrne, E.M.; Mano, J.F. Recent Progress on Polysaccharide-Based Hydrogels for Controlled Delivery of Therapeutic Biomolecules. ACS Biomater. Sci. Eng. 2021, 7, 4102-4127. [CrossRef]

23. Chen, X.; Yang, H.; Yan, N. Shell Biorefinery: Dream or Reality? Chem. Eur. J. 2016, 22, 13402-13421. [CrossRef]

24. El Kadib, A. Green and Functional Aerogels by Macromolecular and Textural Engineering of Chitosan Microspheres. Chem. Rec. 2020, 20, 753-772. [CrossRef]

25. Mohandas, A.; Deepthi, S.; Biswas, R.; Jayakumar, R. Chitosan based metallic nanocomposite scaffolds as antimicrobial wound dressings. Bioact. Mater. 2018, 3, 267-277. [CrossRef]

26. Qu, B.; Luo, Y. A review on the preparation and characterization of chitosan-clay nanocomposite films and coatings for food packaging applications. Carbohydr. Polym. Technol. Appl. 2021, 2, 100-102.

27. Rezaei, F.S.; Sharifianjazi, F.; Esmaeilkhanian, A.; Salehi, E. Chitosan films and scaffolds for regenerative medicine applications: A review. Carbohydr. Polym. 2021, 273, 118631. [CrossRef]

28. Chabbi, J.; Aqil, A.; Katir, N.; Vertruyen, B.; Jerome, C.; Lahcini, M.; El Kadib, A. Aldehyde-conjugated chitosan-graphene oxide glucodynamers: Ternary cooperative assembly and controlled chemical release. Carbohydr. Polym 2020, 230, 115634. [CrossRef]

29. Wrońska, N.; Katir, N.; Miłowska, K.; Hammi, N.; Nowak, M.; Kędzierska, M.; Anouar, A.; Zawadzka, K.; Bryszewska, M.; El Kadib, A.; et al. Antimicrobial effect of chitosan films on food spoilage bacteria. Int. J. Mol. Sci. 2021, 22, 5839. [CrossRef]

30. Wronska, N.; Anouar, A.; El Achaby, M.; Zawadzka, K.; Kedzierska, M.; Miłowska, K.; Katir, N.; Draoui, K.; Rózalska, S.; Piwonski, I.; et al. Chitosan-Functionalized Graphene Nanocomposite Films: Interfacial Interplay and Biological Activity. Materials 2020, 13, 998. [CrossRef] [PubMed]

31. Hammi, N.; Wrońska, N.; Katir, N.; Lisowska, K.; Marcotte, N.; Cacciaguerra, T.; Bryszewska, M.; El Kadib, A. Supramolecular chemistry driven preparation of nanostructured, transformable and biologically-active chitosan-clustered single, binary and ternary metal oxide bioplastics. ACS Appl. Bio Mater. 2019, 2, 61-69.

32. Chabbi, J.; Jennah, O.; Katir, N.; Lahcini, M.; Bousmina, M.; El Kadib, A. Aldehyde-functionalized chitosan-montmorillonite films as dynamically-assembled, switchable-chemical release bioplastics. Carbohydr. Polym. 2018, 183, 287-293. [CrossRef] [PubMed]

33. Blilid, S.; Kędzierska, M.; Wrońska, N.; El Achaby, M.; Katir, N.; Belamie, E.; Alonso, B.; Lisowska, K.; Lahcini, M.; Bryszewska, M.; et al. Phosphorylated Micro- and Nanocellulose-filled chitosan nanocomposites as fully sustainable, biologically active bioplastics. ACS Sustain. Chem. Eng. 2020, 8, 18354-18365. [CrossRef]

34. Blilid, S.; Katir, N.; El Haskouri, J.; Lachini, M.; Royer, S.; El Kadib, A. Phosphorylated micro- vs. nano-cellulose: A comparative study on their surface functionalisation, growth of titanium-oxo-phosphate clusters and removal of chemical pollutants. New J. Chem. 2019, 43, 15555. [CrossRef]

35. Li, H.; Cheng, W.; Liua, K.; Chen, L.; Huang, Y.; Wanga, X.; Lva, Z.; He, J.; Li, C. Reinforced collagen with oxidized microcrystalline cellulose shows improved hemostatic effects. Carbohydr. Polym. 2017, 165, 30-38. [CrossRef] [PubMed]

36. Cheng, W.; He, J.; Chen, M.; Li, D.; Li, H.; Chen, L.; Cao, Y.; Wang, J.; Huang, H. Preparation, Functional Characterization and Hemostatic Mechanism Discussion for Oxidized Microcrystalline Cellulose and Its Composites. Fibers Polym. 2016, 17, 1277-1286. [CrossRef]

37. Schonauer, C.; Tessitore, E.; Barbagallo, G.; Albanese, V.; Moraci, A. The use of local agents: Bone wax, gelatin, collagen, oxidized cellulose. Eur. Spine J. 2004, 13, 89-96. [CrossRef]

38. Brown, A.C.; Barker, T.H. Fibrin-based biomaterials: Modulation of macroscopic properties through rational design at the molecular level. Acta Biomat. 2014, 10, 1502-1514. [CrossRef] 
39. Chen, Z.; Han, L.; Liu, C.; Du, Y.; Hu, X.; Du, G.; Shan, C.; Yang, K.; Wang, C.; Li, M.; et al. A rapid hemostatic sponge based on large, mesoporous silica nanoparticles and N alkylated chitosan. Nanoscale 2018, 10, 20234-22024. [CrossRef]

40. Kheirabadi, B.S.; Scherer, M.R.; Estep, J.S.; Dubick, M.A.; Holcomb, J.B. Determination of efficacy of new hemostatic dressings in a model of extremity arterial hemorrhage in swine. J. Trauma 2009, 67, 450-460. [CrossRef]

41. Zhang, H.; Yang, Y.; Zhou, Z. Phenolic and flavonoid contents of mandarin (Citrus reticulata Blanco) fruit tissues and their antioxidant capacity as evaluated by DPPH and ABTS methods. J. Integr. Agric. 2018, 17, 256-263. [CrossRef]

42. Arnao, M.B.; Cano, A.; Acosta, M. The hydrophilic and lipophilic contribution to total antioxidant activity. Food Chem. 2001, 73, 239-244. [CrossRef]

43. Espinosa, E.; Bascón-Villegas, I.; Rosal, A.; Pérez-Rodríguez, F.; Chinga-Carrasco, G.; Rodríguez, A. PVA/(ligno)nanocellulose biocomposite films. Effect of residual lignin content on structural, mechanical, barrier and antioxidant properties. Int. J. Biol. Macromol. 2019, 141, 197-206. [CrossRef]

44. Zhang, W.; Zhang, Y.; Cao, J.; Jiang, W. Improving the performance of edible food packaging films by using nanocellulose as an additive. Int. J. Biol. Macromol. 2021, 166, 288-296. [CrossRef]

45. El Fawal, G.F.; Omer, A.M.; Temer, T.M. Evaluation of antimicrobial and antioxidant activities for cellulose aceteate films incorporated with Rosemary and Aloe Vera essential oils. J. Food Sci. Technol. 2019, 56, 1510-1518. [CrossRef]

46. Roy, S.; Kim, H.C.; Kim, J.W.; Zhai, L.; Zhu, Q.Y.; Kim, J. Incorporation of melanin nanoparticles improves UV-shielding, mechanical and antioxidant properties of cellulose nanofiber based nanocomposite films. Mater. Today Commun. 2020, $24,100984$. [CrossRef]

47. Poonguzhali, R.; Khaleel Basha, S.; Sugantha Kumari, V. Synthesis and characterization of chitosan-PVP-nanocellulose composites for in-vitro wound dressing application. Int. J. Biol. Macromol. 2017, 105, 111-120. [CrossRef] [PubMed]

48. Naseri, N.; Mathew, A.P.; Girandon, L. Porous electrospun nanocomposite mats based on chitosan-cellulose nanocrystals for wound dressing: Effect of surface characteristics of nanocrystals. Cellulose 2015, 22, 521-534. [CrossRef]

49. Dong, S.; Hirani, A.A.; Colacino, K.R.; Lee, Y.W.; Roman, M. Cytotoxicity and Cellular Uptake of Cellulose Nanocrystals. Nano Life 2012, 2, 1-11. [CrossRef]

50. Rodríguez, K.; Gatenholm, P.; Renneckar, S. Electrospinning cellulosic nanofibers for biomedical applications: Structure and in vitro biocompatibility. Cellulose 2012, 19, 1583-1598. [CrossRef]

51. Mathew, A.P.; Oksman, K.; Karim, Z.; Liu, P.; Khan, S.A.; Naseri, N. Process scale up and characterization of wood cellulose nanocrystals hydrolysed using bioethanol pilot plant. Ind. Crop. Prod. 2014, 58, 212-219. [CrossRef]

52. Rokstad, A.M.; Brekke, O.L.; Steinkjer, B.; Ryan, L.; Kolláriková, G.; Strand, B.L.; Skjåk-Bræk, G.; Lambris, J.D.; Lacík, I.; Mollnes, T.E.; et al. The induction of cytokines by polycation containing microspheres by a complement dependent mechanism. Biomaterials 2013, 34, 621-630. [CrossRef]

53. Burd, A.; Kwok, C.H.; Hung, S.C.; Chan, H.S.; Gu, H.; Lam, W.K.; Huang, L. A comparative study of the cytotoxicity of silver-based dressings in monolayer cell, tissue explant, and animal models. Wound Repair Regen. 2007, 15, 94-104. [CrossRef] [PubMed]

54. Čolid, M.; Mihajlovid, D.; Mathew, A.; Naseri, N.; Kokol, V. Cytocompatibility and immunomodulatory properties of wood based nanofibrillated cellulose. Cellulose 2015, 22, 763-778.

55. Paddle-Ledinek, J.E.; Nasa, Z.; Cleland, H.J. Effect of Different Wound Dressings on Cell Viability and Proliferation. Plast. Reconstr. Surg. 2006, 117, 110-118. [CrossRef]

56. Petersen, N.; Gatenholm, P. Bacterial cellulose-based materials and medical devices: Current state and perspectives. Appl. Microbiol. Biotechnol. 2011, 91, 1277-1286. [CrossRef]

57. Aimonen, K.; Suhonen, S.; Hartikainen, M.; Lopes, V.R.; Norppa, H.; Ferraz, N.; Catalán, J. Role of Surface Chemistry in the In Vitro Lung Response to Nanofibrillated Cellulose. Nanomaterials 2021, 11, 389. [CrossRef]

58. Jabaut, J.; Ather, J.L.; Taracanova, A.; Poynter, M.E.; Ckless, K. Mitochondria-targeted drugs enhance Nlrp3 inflammasomedependent IL-1beta secretion in association with alterations in cellular redox and energy status. Free Radic. Biol. Med. 2013, 60, 233-245. [CrossRef]

59. Bulua, A.C.; Simon, A.; Maddipati, R.; Pelletier, M.; Park, H.; Kim, K.Y.; Sack, M.N.; Kastner, D.L.; Siegel, R.M. Mitochondrial reactive oxygen species promote production of proinflammatory cytokines and are elevated in TNFR1-associated periodic syndrome (TRAP). J. Exp. Med. 2011, 208, 519-533. [CrossRef]

60. Zhou, R.; Yazdi, A.S.; Menu, P.; Tschopp, J. A role for mitochondria in NLRP3 inflammasome activation. Nature 2011, 469, 221-225. [CrossRef] [PubMed]

61. Sunasee, R.; Araoye, E.; Pyram, D.; Usha, D.; Hemraz, D.; Boluk, Y.; Ckless, K. Cellulose nanocrystal cationic derivative induces NLRP3 inflammasome-dependent IL-1 $\beta$ secretion associated with mitochondrial ROS production. Biochem. Biophys. Rep. 2015, 4, 1-9. [CrossRef]

62. Tyagi, N.; Ovechkin, A.V.; Lominadze, D.; Moshal, K.S.; Tyagi, S.C. Mitochondrial mechanism of microvascular endothelial cells apoptosis in hyperhomocysteinemia. J. Cell Biochem. 2006, 98, 1150-1162. [CrossRef] [PubMed]

63. Wei, J.; Liu, M.; Liu, H.; Wang, H.; Wang, F.; Zhang, Y.; Lin, X. Oleanolic acid arrests cell cycle and induces apoptosis via ROS-mediated mitochondrial depolarization and lysosomal membrane permeabilization in human pancreatic cancer cells. $J$. Appl. Toxic 2012, 33, 756-765. [CrossRef] [PubMed] 
64. Wang, L.; Mao, L.; Qi, F.; Li, X.; Ullah, W.M.; Zhon, M.; Shi, Z.; Yan, G. Synergistic effect of highly aligned bacterial cellulose/gelatin membranes and electrical stimulation on directional cell migration for accelerated wound healing. Chem. Eng. J. 2021, $424,130563$. [CrossRef]

65. Bacakova, M.; Pajorova, J.; Sopuch, T.; Bacakova, L. Fibrin-Modified Cellulose as a Promising Dressing for Accelerated Wound Healing. Materials 2018, 11, 2314. [CrossRef] [PubMed]

66. Dvorankova, B.; Smetana, K., Jr.; Vacik, J.; Jelinkova, M. Cultivation of keratinocytes on poly HEMA and their migration after inversion. Folia Biol. 1996, 42, 83-86.

67. Collins, A.R.; Dobson, V.L.; Dusinska, M.; Kennedy, G.; Stetina, R. The comet assay: What can it really tell us? Mutat. Res. 1997, 375, 183-193. [CrossRef]

68. Collins, A.R.; Oscoz, A.A.; Brunborg, G.; Gaivão, I.; Giovannelli, L.; Kruszewski, M.; Smith, C.C.; Stetina, R. The comet assay: Topical issues. Mutagen. Adv. 2008, 23, 143-151. [CrossRef] [PubMed]

69. Donaldson, K.; Aitken, R.; Tran, L.; Stone, V.; Duffin, R.; Forrest, G.; Alexander, A. Carbon nanotubes: A review of their properties in relation to pulmonary toxicology and workplace safety. Toxicol. Sci. 2006, 92, 5-22. [CrossRef] [PubMed]

70. Coelho, F.; Cavicchioli, M.; Specian, S.S.; Scarel-Caminaga, R.M.; Penteado, L.; Medeiros, A. Bacterial cellulose membrane functionalized with hydroxiapatite and anti-bone morphogenetic protein 2: A promising material for bone regeneration. PLoS ONE 2019, 14, e0221286.

71. Coelho, F.; do Vale Braido, G.V.; Cavicchioli, M.; Mendes, L.S.; Specian, S.S.; Franchi, L.P. Toxicity of therapeutic contact lenses based on bacterial cellulose with coatings to provide transparency. Contact Lens Anterior Eye 2019, 42, 512-519. [CrossRef]

72. Moreira, S.; Silva, N.B.; Almeida-Lima, J.; Rocha, H.A.O.; Medeiros, S.R.B.; Alves, C.; Gama, F.M. BC nanofibres: In vitro study of genotoxicity and cell proliferation. Toxicol. Lett. 2009, 189, 235-241.

73. Prasa, D. The ability of thrombin inhibitors to reduce the thrombin activity generated in plasma on extrinsic and intrinsic activation. Thromb Haemost. 1997, 77, 498-503. [CrossRef]

74. Kolodziejczyk-Czepas, J.; Sieradzka, M.; Moniuszko-Szajwaj, B.; Nowak, P.; Oleszek, W.; Stochmal, A. Phenolic fractions from nine Trifolium species modulate the coagulant properties of blood plasma in vitro without cytotoxicity towards blood cells. $J$. Pharm. Pharmacol. 2018, 70, 413-425. [CrossRef] [PubMed]

75. Kolodziejczyk-Czepas, J.; Ponczek, M.; Sady-Janczak, M.; Pilarski, R.; Bukowska, B. Extracts from Uncaria tomentosa as antiplatelet agents and thrombin inhibitors-The in vitro and in silico study. J. Ethnopharmacol. 2020, 113494. [CrossRef]

76. Erel, O. A novel automated direct measurement method for total antioxidant capacity using a new generation, more stable ABTS radical cation. Clin. Biochem. 2004, 37, 277-285. [CrossRef]

77. Mosmann, T. Rapid colorimetric assay for cellular growth and survival: Application to proliferation and cytotoxicity assays. $J$. Immunol. Methods 1983, 65, 55-63. [CrossRef]

78. Yoo, D.J.; Ravichandiran, P.; Subramaniyan, S.A.; Kim, S.-Y.; Kim, J.-S.; Park, B.-H.; Shim, K.S. Synthesis and anticancer evaluation of novel 1,4-naphthoquinone derivatives containing a phenylamino-sulfanyl moiety. ChemMedChem 2019, 14, 512.

79. Myhre, O.; Andersen, J.M.; Aarnes, H.; Fonnum, F. Evaluation of the probes $2^{\prime}, 7^{\prime}$-dichlorofluorescin diacetate, luminol, and lucigenin as indicators of reactive species formation. Biochem. Pharmacol. 2003, 65, 1575-1582. [CrossRef]

80. Ravichandiran, P.; Masłyk, M.; Sheet, S.; Janeczko, M.; Premnath, D.; Kim, A.R.; Yoo, D.J. Synthesis and Antimicrobial Evaluation of 1,4-Naphthoquinone Derivatives as Potential Antibacterial Agents. ChemistryOpen 2019, 8, 589-600. [CrossRef] [PubMed]

81. Ravichandiran, P.; Sheet, S.; Premnath, D.; Kim, A.R.; Yoo, D.J. 1,4-Naphthoquinone Analogues: Potent Antibacterial Agents and Mode of Action Evaluation. Molecules 2019, 24, 1437. [CrossRef] [PubMed]

82. Feldkamp, T.; Kribben, A.; Weinberg, J.M. Assessment of mitochondrial membrane potential in proximal tubules after hypoxiareoxygenation. Am. J. Physiol. Ren. Physiol. 2005, 288, 1092-1102. [CrossRef] [PubMed]

83. Entschladen, F.; Drell, T.L.; Lang, K.; Masur, K.; Palm, D.; Bastian, P.; Niggemann, B.; Zaenker, K.S. Analysis methods of human cell migration. Exp. Cell Res. 2005, 307, 418-426. [CrossRef]

84. Boyden, S. The chemotactic effect of mixtures of antibody and antigen on polymorphonuclear leucocytes. J. Exp. Med. 1962, 115, 453-466. [CrossRef]

85. Singh, N.P.; McCoy, M.T.; Tice, R.R.; Schneider, E.L. A simple technique for quantitation of low levels of DNA damage in individual cells. Exp. Cell Res. 1988, 175, 184-191. [CrossRef]

86. Blasiak, J.; Kowalik, J. A comparison of the in vitro genotoxicity of tri-and hexavalent chromium. Mutat. Res. 2000, 469, 135-145. [CrossRef] 